\title{
Kind und Referendariat
}

\author{
Katrin Stegemann-Siebert \\ Staatsanwältin, Kiel
}

Meine älteste Tochter wurde zwei Wochen nach meiner mündlichen Prüfung zum 1. Staatsexamen geboren. Wie sollte es nun weitergehen? Dank recht gutem Ergebnis und einem Kind konnte ich Beginn und Ort des Referendariats frei wählenwählen. Ich entschloss mich, zum nächstmöglichen Termin in meiner Heimatstadt Kiel anzufangen. Da ich vor dem Studium schon etwas anderes gemacht hatte und nicht mehr ganz so jung war, wollte ich die Fortsetzung meiner Ausbildung nicht unnötig lange hinauszögern, außerdem wollte ich nach der ganzen Theorie nun auch endlich die Praxis kennenlernen. Die Kleine war also vier Monate alt, als ich die erste Station bei der Staatsanwaltschaft antrat. Meine Schwiegermutter war gerade in Rente gegangen und hatte sich bereit erklärt, ihre Enkelin zu betreuen, so dass ich ein gutes Gefühl dabei hatte, mein Baby in andere Hände zu geben.

Ich wurde gleich am ersten Tag vom Ausbildungsleiter beiseite genommen, und mir wurde versichert, dass ich jede Unterstützung bekommen würde. Sollte es Probleme mit der Kinderbetreuung geben, sollte ich mich doch bitte melden, dann würden wir gemeinsam eine Lösung finden. So oder ähnlich liefen eigentlich alle Gespräche am Anfang der Stationen ab, jeder bemühte sich, Steine aus dem Weg zu räumen.

So durchlief ich also meine Stationen: die Staatsanwaltschaft war sehr interessant, aber vielleicht am schwierigsten zu bewältigen. Die Situation Beruf und Kind war mir noch völlig neu, ich stillte noch und musste oft genug aufpassen, dass meine weiße Bluse vor Gerichtsterminen nicht bekleckert wurde. Mehr als einmal tauchte ich mit Baby im Tragetuch in der Dienststelle auf, um Akten zu holen oder zurückzubringen.

Dann folgte das Landgericht. Zivilrecht war noch nie meine große Leidenschaft, so dass ich keine allzu große Begeisterung entwickelte. Aber auch hier musste ich nur an den Sitzungstagen „meiner“ Richterin anwesend sein. Dazu kamen natürlich die AG-Tage.

$\mathrm{Da}$ ich vor meinem Studium bereits eine dreijährige Ausbildung in der Steuerverwaltung absolviert hatte, fand ich, dass ich auf eine „klassische“ Verwaltungsstation verzichten konnte und ging statt dessen in der Zeit an die hiesige Fachhochschule für öffentliche Verwaltung, an der ich einst selbst Studentin gewesen war. Hier unterrichtete ich in erster Linie - meistens Familienrecht -, korrigierte Klausuren, bereitete aber auch einen kleinen Rechtsstreit der Schule vor. In dieser Zeit wurde meine Freude am Unterrichten geweckt; so bin ich dort bis heute als nebenamtliche Lehrbeauftragte tätig.

Wegen meiner Vorliebe für das öffentliche Recht suchte ich mir für die Anwaltsstation eine Kanzlei mit diesem Schwerpunkt. Ich musste allerdings feststellen, dass öffentliches Recht in der Praxis weniger Verfassungsrecht als Baurecht oder Konkurrentenklagen von Beamten bedeutete, was ich bei Weitem nicht so spannend fand. Außerdem bestand meine Aufgabe dort lediglich im Erstellen von Schriftsätzen, die eine gewisse Mindestlänge aufweisen mussten, während ich die praktische Anwaltstätigkeit so gut wie gar nicht kennenlernte und auch nur wenig bis keinen Mandant(inn)enkontakt hatte.

Als ich Referendarin war, gab es noch die „Wahlpflichtstation“, von vielen auch als Tauchstation genutzt, um sich auf das Examen vorzubereiten. Das tat ich jedoch nicht, sondern kehrte in vertraute Gefilde zurück, nämlich in das Finanzamt. Dies war aufgrund meiner Vorbildung eine sehr erfolgreiche Station, auf die die Examensklausuren folgten.

Danach folgte der Höhepunkt des Referendariates: die Wahlstation, die ich als guest lecturer am Trinity College in Dublin verbrachte. Meine Schwiegermutter hatte sich bereit erklärt, mich als „Kinderfrau“ zu begleiten, und so mietete ich für uns drei ein kleines Haus, unterrichtete Staatsrecht im Studiengang „German and law“ und genoss es, eine andere Stadt kennenzulernen inklusive einer irischen Krabbelgruppe, die ich mit meiner inzwischen zwei Jahre alten Tochter besuchte. Wieder zurück igelte ich mich noch einmal ein, um dann die mündliche Prüfung abzulegen.

Rückblickend kann ich sagen, dass ich sehr viel Glück mit meinem Referendariat hatte. Zum einen hatte ich natürlich die Unterstützung meiner Familie, zum anderen aber auch durchweg verständnisvolle Ausbilder, die mir flexible Arbeitszeiten gelassen haben. Da es in den meisten Fällen wenig Anwesenheitspflichten gibt, ist das Referendariat mit Kindern gut zu bewältigen, wenn man die Stationen entsprechend wählt. Natürlich gab es auch Abstriche: eine Station in einer Großkanzlei wäre sicherlich eher nicht in Betracht gekommen, ebenso habe ich an einigen der Angebote, wie z.B. eine einwöchige Reise nach Berlin, nicht teilgenommen, weil ich meine Tochter nicht so lange alleine lassen wollte. Da ich die Nachmittage meistens mit ihr verbrachte, gehörten die Abende weitestgehend den Büchern oder Akten, so dass mein gesellschaftliches Leben wesentlich eingeschränkter war als zu Zeiten des Studiums. Ich fand aber trotz allem die Zeit, mich im Referendarrat zu engagieren und weiterhin an der Fachhochschule zu unterrichten.

Ich kann jedenfalls sagen, dass das Referendariat auch mit Kind gut zu bewältigen ist. Durch die Möglichkeit, viel zuhause zu arbeiten, ist es oft sogar leichter als das eigentliche Berufsleben. Man lernt sehr schnell, die verfügbare Zeit effektiv zu nutzen. Fehlen tut allenfalls die Spontaneität, die den Kolleg(inn)en möglich ist, zumindest solange das Kind noch keine festen Betreuungszeiten zum Beispiel in einer Kita hat.

Inzwischen habe ich drei Kinder und arbeite nach einigen Jahren als Rechtsanwältin bei der Staatsanwaltschaft. Auch dort bewegt sich etwas, und ich habe es als erste in unserer Behörde ausgehandelt, dass ich, anstatt in Elternzeit zu gehen, bis zum ersten Geburtstag meines Sohnes weitgehend von zuhause aus arbeiten darf. Manchmal muss man eben einfach versuchen, etwas Neues einzuführen. 